\title{
Fatty acid composition and desaturase gene expression in flax (Linum usitatissimum L.)
}

\author{
Dinushika Thambugala $\cdot$ Sylvie Cloutier
}

Received: 10 December 2013 /Revised: 29 April 2014 / Accepted: 2 May 2014 / Published online: 29 May 2014

(C) The Author(s) 2014. This article is published with open access at Springerlink.com

\begin{abstract}
Little is known about the relationship between expression levels of fatty acid desaturase genes during seed development and fatty acid (FA) composition in flax. In the present study, we looked at promoter structural variations of six FA desaturase genes and their relative expression throughout seed development. Computational analysis of the nucleotide sequences of the $s a d 1, \operatorname{sad} 2, f a d 2 a, f a d 2 b, f a d 3 a$ and $f a d 3 b$ promoters showed several basic transcriptional elements including CAAT and TATA boxes, and several putative target-binding sites for transcription factors, which have been reported to be involved in the regulation of lipid metabolism. Using semi-quantitative reverse transcriptase PCR, the expression patterns throughout seed development of the six FA desaturase genes were measured in six flax genotypes that differed for FA composition but that carried the same desaturase isoforms. FA composition data were determined by phenotyping the field grown genotypes over four years in two environments. All six genes displayed a bell-shaped pattern of expression peaking at 20 or 24 days after anthesis. $\mathrm{Sad} 2$ was the most highly expressed. The expression of all six desaturase genes did not differ significantly between
\end{abstract}

Electronic supplementary material The online version of this article (doi:10.1007/s13353-014-0222-0) contains supplementary material, which is available to authorized users.

D. Thambugala $\cdot$ S. Cloutier

Department of Plant Science, University of Manitoba, 66 Dafoe Rd,

Winnipeg, MB, Canada R3T 2N2

D. Thambugala $\cdot \mathrm{S}$. Cloutier

Cereal Research Centre, Agriculture and Agri-Food Canada, 195

Dafoe Rd, Winnipeg, MB, Canada R3T 2M9

Present Address:

S. Cloutier $(\bowtie)$

Eastern Cereal and Oilseed Research Centre, K.W. Neatby Building, 960 Carling Ave, Ottawa, ON, Canada K1A 0C6

e-mail: Sylvie.J.Cloutier@agr.gc.ca genotypes ( $\mathrm{P}=0.1400)$, hence there were no correlations between FA desaturase gene expression and variations in FA composition in relatively low, intermediate and high linolenic acid genotypes expressing identical isoforms for all six desaturases. These results provide further clues towards understanding the genetic factors responsible for FA composition in flax.

Keywords $\mathrm{fad} \cdot$ Fatty acid composition $\cdot$ Fatty acid desaturase $\cdot$ Flax $\cdot$ Gene expression $\cdot$ Promoter analysis $\cdot$ sad

\section{Introduction}

Flax (Linum usitatissimum L.) is the leading source of plantbased omega-3 fatty acids (FAs) praised for their health benefits in humans and animals. Oilseed flax, also known as linseed, generally contains $40-50 \%$ oil and its quality is largely determined by its FA composition (Green 1986; Cloutier et al. 2010). Linseed oil is primarily composed of palmitic (PAL, C16:0; 6\%), stearic (STE, C18:0 4.4\%), oleic (OLE, C18:1 24.2\%), linoleic (LIO, C18:2 15.3\%) and linolenic (LIN, C18:3 50.1\%) acids (Muir and Westcott 2003). The high levels of alpha-linolenic acid (ALA or LIN) and moderate levels of LIO in linseed oil not only contribute to a healthy diet but are considered essential FAs because humans lack the $\Delta^{12}$ and $\Delta^{15}$ desaturase enzymes that convert OLE to LIO and LIO to LIN, respectively (Damude and Kinney 2008). Humans can use these FAs as substrates for further elongation and desaturation leading to the formation of very long chain polyunsaturated FAs (VLCPUFAs) like ecosapentaenoic acid (EPA, C22:5), docosahexaenoic acid (DHA, C22:6) and arachidonic acid (AA, C20:4) (Warude et al. 2006). These VLCPUFAs also have health benefits and studies have established their important role in reducing total and low-density lipoprotein (LDL) cholesterol levels in 
humans and preventing chronic diseases including cardiovascular diseases, hormonal cancers and arthritis (Oomah 2001; Wiesenfeld et al. 2003; Ander et al. 2004; Dyer et al. 2008). However, the high LIN content of flaxseed oil makes it more susceptible to oxidation and rancidity (Zuk et al. 2012), thus limiting its use as an edible oil, but simultaneously providing it with unique drying properties that makes it valuable in various industrial applications (Green 1986).

Genetic control of FA biosynthesis in flax has been studied and many of the genes encoding the enzymes that perform FA synthesis have been identified and characterized (Green 1986; Fofana et al. 2004, 2006; Sorensen et al. 2005; Vrinten et al. 2005; Krasowska et al. 2007; Khadake et al. 2009; Banik et al. 2011; Thambugala et al. 2013). FA desaturation and elongation are important biochemical processes that drive the multistep FA biosynthetic pathway in a sequential manner, leading to synthesis of polyunsaturated FAs (Warude et al. 2006; Khadake et al. 2011). Fatty acid desaturases (FADs) are the key enzymes that introduce double bonds into FA acyl chains in a stepwise manner starting from STE (Los and Murata 1998; Shanklin and Cahoon 1998; Smooker et al. 2011). The desaturation of STE is sequentially catalyzed by desaturases namely, stearoyl-ACP desaturase (SAD) (Singh et al. 1994; Jain et al. 1999), fatty acid desaturase 2 (FAD2) (Krasowska et al. 2007; Khadake et al. 2009) and fatty acid desaturase 3 (FAD3) (Vrinten et al. 2005; Banik et al. 2011). In flax, these three enzymes are encoded by duplicated genes (Fofana et al. 2010). The two FAD3 enzymes, FAD3A and FAD3B, have been shown to be the major enzymes controlling LIN content in linseed (Vrinten et al. 2005).

Although the genetic variability of desaturase genes and their impact on FA composition in flax have been studied (Thambugala et al. 2013), only two studies on the regulation and expression of sad and $\mathrm{fad}$ genes during seed development have been reported (Fofana et al. 2006; Banik et al. 2011). Fofana et al. (2006) reported that the expression of sad and $\mathrm{fad} 2$ genes in flax was modulated during seed development whereas Banik et al. (2011) found that the expression patterns of $f a d 3 a$ and $f a d 3 b$ were highly correlated with LIN accumulation during seed development.

In our previous study, we characterized the genetic variability for $s a d 1, s a d 2$, fad $2 a, f a d 2 b, f a d 3 a$ and $f a d 3 b$ genes in flax by sequencing the six genes from 120 flax accessions (Thambugala et al. 2013). Between five and 21 alleles corresponding to two to seven isoforms were identified for the six desaturases. Thirty-four accessions had an identical isoform composition for all six desaturase genes but their FA composition varied significantly. We hypothesized that FA composition differences in these lines could result from differential expression of the desaturase genes during seed development. Based on this hypothesis, this study had three goals. First, to quantify the expression levels of the desaturase genes at different stages of seed development by semi-quantitative reverse transcriptase (RT)-PCR in relatively low, intermediate and high LIN genotypes expressing identical isoforms for all six desaturases. Second, to study the structural differences in the promoter region of the six desaturase genes. Third, to correlate these structural and expression data with FA composition as determined by phenotyping the field grown genotypes during four years at two locations with the overall objective of gaining a greater understanding of the genetic factors controlling the FA composition in flax.

\section{Materials and methods}

\section{Plant material}

FA composition of 34 flax accessions carrying identical isoforms for the desaturase genes $s a d 1, s a d 2$, fad $2 a$, fad $2 b$, fad $3 a$ and $f a d 3 b$ were analysed as previously described (Thambugala et al. 2013) and six linseed genotypes showing significantly different $(\mathrm{P}<0.05)$ FA profiles were selected for this study (ESM 1). These six genotypes, including two high (UGG5-5, M5791), two intermediate (FP2270, CN30861) and two relatively low LIN (CN97334, CN97407), were grown in a growth chamber under the following conditions: $22{ }^{\circ} \mathrm{C}$ with a $16-\mathrm{h}$ photoperiod at a photon density of approximately $145 \mu \mathrm{E} \cdot \mathrm{m}^{-2} \cdot \mathrm{s}^{-2}$ (Fofana et al. 2004). Flowers were tagged at anthesis and developing bolls harvested at $8,12,16$, 20,24, 28 and 32 days after anthesis (DAA) were immediately frozen in liquid nitrogen where they were stored until RNA extraction.

\section{RNA extraction}

Total RNA was extracted from 8-32 DAA developing bolls of each genotype using the RNA extraction procedure described in Banik et al. (2011). For each extraction, $0.2 \mathrm{~g}$ of bolls were used. Final total RNA pellets were resuspended in $50 \mu \mathrm{l}$ RNase-free water and stored at $-80^{\circ} \mathrm{C}$. The RNA was quantified by nano-spectrophotometer (Implen $\mathrm{GmbH}$, Munich, Germany).

\section{First strand cDNA synthesis}

To remove any potential remnant DNA, total RNA from each developmental stage and genotype was treated with TURBO DNase according to the manufacturer's instructions (Ambion, Austin, Texas, USA). The DNase treated RNA was used as a template to synthesize first strand cDNA using oligo(dT) primer and Superscript ${ }^{\mathrm{TM}}$ II reverse transcriptase followed by RNaseH treatment as per the manufacturer's recommendations (Invitrogen, Carlsbad, CA, USA). An amount of $800 \mathrm{ng}$ total RNA was used to synthesize the cDNA in three independent $20 \mu \mathrm{l}$ reactions for each developmental stage and 
each genotype. Pooled cDNA samples of each developmental stage and genotype were stored at $-20{ }^{\circ} \mathrm{C}$.

\section{cDNA quantification}

A fluorometric method was used to precisely quantify the first strand cDNA. In this method, the RNA was digested and the single-stranded cDNA was quantified by fluorescence using RiboGreen (Invitrogen) as described by Libus and Storchová (2006). cDNA quantification was performed in duplicate for each development stage of each genotype.

\section{RT-PCR of sad and fad genes}

Semi-quantitative RT-PCR was performed using the quantified cDNA samples from 8-32 DAA using 28 cycles as previously recommended (Kumar et al. 2013). Gene-specific PCR primers (Table 1) for $s a d 1$, sad2, fad $2 a, f a d 2 b, f a d 3 a$ and $f a d 3 b$ were designed using Primer Express (Applied Biosystems) and Primer 3 software (Rozen and Skaletsky 2000). Optimized amplification reactions $(25 \mu \mathrm{L})$ contained 4 ng cDNA, 1X PCR buffer, $1.5 \mathrm{mM} \mathrm{MgCl}_{2}, 0.8 \mathrm{mM}$ dNTPs, $0.4 \mu \mathrm{M}$ each primer and $1.5 \mathrm{U}$ Taq DNA polymerase. The PCR reactions were first denatured at $94{ }^{\circ} \mathrm{C}$ for $5 \mathrm{~min}$ followed by 28 cycles consisting of $94^{\circ} \mathrm{C}$ for $30 \mathrm{~s} ; 62^{\circ} \mathrm{C}$ for $30 \mathrm{~s}$ and $72{ }^{\circ} \mathrm{C}$ for $60 \mathrm{~s}$, prior to a final extension at $72^{\circ} \mathrm{C}$ for $10 \mathrm{~min}$. RT-PCR products were resolved on $2.5 \%$ agarose gels stained with ethidium bromide. The flax adenine phosphoribosyltransferase 1 (aptl) gene was used as a reference control in all RT-PCR experiments (Banik et al. 2011). Three independent RT-PCR replications were performed for each gene, each developmental stage and genotype, including aptl. The expression of the target genes relative to the reference gene apt1 was evaluated by densitometric analysis of the signal strength of the semi-quantitative RT-PCRs with the AlphaImagerHP software (version 3.4, proteinsimple, Santa Clara, CA, USA). Desaturase gene to apt1 ratios were calculated by dividing the background corrected signal of the PCR amplicon of the desaturase gene to that of apt1.

\section{Promoter analysis of $\mathrm{sad}$ and $\mathrm{fad}$ genes}

Promoter sequences corresponding to bases -800 to +200 relative to the transcription start site (TSS) of sad and fad genes were obtained from the six flax genotypes by sequencing the amplicons with Big-Dye V3.1 Terminator chemistry and resolving them on an ABI 3130xl Genetic Analyser (Applied BioSystems, Foster City, CA, USA). All sequences were processed using PHRED (Ewing et al. 1998) and assembled with CAP3 (Huang and Madan 1999) as implemented in the internal data pipeline called SOOMOS v0.6 (T. Banks, personal communication). Sequence alignments were performed with Clustal W (Thompson et al. 1994). TSSs were identified using the bioinformatics pipeline for TSS signals (http://fruitfly.org/ seq tools/promoter.html) (Reese 2001). Promoter analysis was performed with PLAnt Cis-acting regulatory DNA Elements (PLACE) (Higo et al. 1999) and PLANT Promoter Analysis Navigator (PlantPAN) (http://plantpan.mbc.nctu.edu.tw/seq analysis.php) (Chang et al. 2008).

Fatty acid composition

Field plots of the 34 flax accessions were grown in a type 2 modified augmented design (MAD) (Lin and Poushinsky 1985 ) at the Kernen farm near Saskatoon (SK, Canada) and at the Morden Research Station (MB, Canada) in 2009, 2010, 2011 and 2012 (ESM 1). FA composition and oil content (OIL) were obtained from all eight field experiments as previously described (Thambugala et al. 2013).

Statistical analysis

The phenotypic data for FA composition and OIL (ESM 1) were adjusted for soil heterogeneity based on the MAD statistical analysis method using the recently described pipeline (You et al. 2013). Variance components were calculated using adjusted phenotypic data to determine the effect of year, location, genotype and their interactions on FA composition and OIL using the PROC GLM procedure (SAS Institute, Cary, NC, USA). To assess the differences in FA composition among the six genotypes, one-way analysis of variance (ANOVA) was used followed by the Duncan's multiple range comparison test at 0.05 probability level. A similar analysis was performed to determine statistical significance between the ratios of FA desaturase gene to aptl of the six desaturase genes, across all six genotypes and for all seven stages of seed development. All statistical analyses were carried out using SAS v9.2 (SAS Institute, Cary, NC, USA).

\section{Results}

Fatty acid composition

The FA composition of the 34 flax accessions with identical isoform composition for all six desaturase genes displayed significant variations $(\mathrm{P}<0.0001)$ in $\mathrm{LIN}$ content ranging from 46 to $72 \%$ (Fig. 1). Six of those accessions were selected on the basis of their significantly different $(\mathrm{P}<0.05)$ FA compositions. All five FAs showed significant differences across the six genotypes (Fig. 2). UGG5-5 and M5791 had high LIN but low LIO content. In contrast, CN97334 and CN97407 had lower LIN but higher LIO than UGG5-5 and M5791. Significant FA compositional variations were also found for PAL, STE and OLE (Fig. 2). 
Table 1 Sequences and melting temperature of primers used for semi-quantitative RT-PCR and promoter analysis (amplification and sequencing)

\begin{tabular}{|c|c|c|c|}
\hline Gene & Primer name & Sequence $\left(5^{\prime}\right.$ to $\left.3^{\prime}\right)$ & $\operatorname{Tm}\left({ }^{\circ} \mathrm{C}\right)$ \\
\hline \multirow[t]{2}{*}{ apt1 } & APT1-319 F & TAGAGCTGACCAGGACAAACA & 62 \\
\hline & APT1-409R & GTTTATGAATGCGCTTGTCTCA & 62 \\
\hline \multirow[t]{2}{*}{ sadl } & SAD1-F770 & TCGCAGCAGACGAGAAACG & 60 \\
\hline & SAD1-R840 & AGGGTCGATCTCGAAGAGCTT & 58 \\
\hline \multirow[t]{2}{*}{$\operatorname{sad} 2$} & SAD2-F202 & AAGCTGGAGATCTTTAAGTCCCTTGA & 59 \\
\hline & SAD2-R307 & GTTCGGGCAGGAAATCTTGT & 58 \\
\hline \multirow[t]{2}{*}{$f a d 2 a$} & FAD2A-F873 & CGTGGATCGAGACTACGGGTTA & 60 \\
\hline & FAD2A-R942 & ATGGTGCGCGACATGTGT & 58 \\
\hline \multirow[t]{2}{*}{$f a d 2 b$} & FAD2B-F496 & TGGCACTCAAAGTACCTCAACAA & 58 \\
\hline & FAD2B-R571 & AAGGCCAGCCGAGAGTGA & 58 \\
\hline \multirow[t]{2}{*}{$f a d 3 a$} & FAD3A-F40 & GACTTCAAAACTGTGGCTCT & 55 \\
\hline & FAD3A-R132 & GATAGCCACACCATTGGTGC & 62 \\
\hline \multirow[t]{2}{*}{$f a d 3 b$} & FAD3B-F662 & GCAGCGGTCTTGATTTCAACA & 48 \\
\hline & FAD3B-R759 & ATTTTGAGGACCGGAGCGAA & 50 \\
\hline \multicolumn{4}{|c|}{ Promoter analysis } \\
\hline \multirow[t]{4}{*}{ sadl } & SAD1-F53350 & AATGCCTCCAAAGTGCTCTC & 59 \\
\hline & SAD1-R54516 & GCTTACTTGGTGGAGGTGGA & 60 \\
\hline & SAD1-F53628 & TTTGGTGACTCGAAAGTTCT & 55 \\
\hline & SAD1-R53974 & CATATGACATTGCAAGACGA & 56 \\
\hline \multirow[t]{4}{*}{$\operatorname{sad} 2$} & SAD2-F10585 & CGTCCCAATTGATGACAATG & 60 \\
\hline & SAD2-R11671 & TGGAATTGAAAGTGGAAGCA & 59 \\
\hline & SAD2-F10975 & CCAAAGTGCTCTCTACTTGC & 55 \\
\hline & SAD2-R11296 & GCGTTTCATCAGTTCTATCG & 56 \\
\hline \multirow[t]{4}{*}{$f a d 2 a$} & FAD2A-F22 & CGGCGATTTTGAAGTGCAT & 62 \\
\hline & FAD2A-R868 & CTCACCGAGCGTGAATGGT & 62 \\
\hline & FAD2A-F252 & GCССТССТTCATATTCTTCT & 55 \\
\hline & FAD2A-R566 & TCCTTTCCAGTTTTCAGTTG & 55 \\
\hline \multirow[t]{4}{*}{$f a d 2 b$} & FAD2B-F1036 & AAGGGTGATGGTCTTGATGC & 60 \\
\hline & FAD2B-R2094 & AGGGACGGCTTTCTTGATCT & 60 \\
\hline & FAD2B-F1239 & TACCCTAAAGTGATCAATGG & 53 \\
\hline & FAD2B-R1569 & AGCAAGTAGTGCTATCCTGA & 53 \\
\hline \multirow[t]{4}{*}{$f a d 3 a$} & FAD3A-F949 & TCGATTGCAAAGCAAGAGAG & 59 \\
\hline & FAD3A-R2018 & AACGGCGAAGCTGAGGAT & 61 \\
\hline & FAD3A-F1228 & TTAGTCGATTTCACCCTAGC & 55 \\
\hline & FAD3A-R1503 & AACGGTTGTTGTTACTTGCT & 55 \\
\hline \multirow[t]{4}{*}{$f a d 3 b$} & FAD3B-F15266 & CCCAACCCATTACATGACG & 60 \\
\hline & FAD3B-R16252 & GCTGAGGATGACAAGGAGGT & 59 \\
\hline & FAD3B-F15435 & AACATTGCAATTCAGAGTCC & 55 \\
\hline & FAD3B-R15777 & TCTGCTCTTTATTGGGTTTC & 55 \\
\hline
\end{tabular}

Sad and fad gene expression during seed development

A semi-quantitative RT-PCR method was used to study expression of the six FA desaturases during the seed developmental stages of flax from 8-32 DAA in six flax genotypes (ESM 2). With the exception of sad1, expression was significantly modulated $(\mathrm{P}<0.0001)$ for the other desaturases during seed development (ESM 3). All six genes followed a similar pattern where gene expression tended to increase from eight to
20 DAA, peaked at 20 or 24 DAA and decreased during the later stages of seed maturation (Fig. 3). Sad2 was the most highly expressed gene (ESM 2) throughout all stages of seed development, peaking at 24DAA (Fig. 3). Sad1 expression was lower than $s a d 2$ and generally remained more constant throughout all developmental stages (Fig. 3).

Fad2 and fad 3 displayed a similar pattern where gene expression increased from eight to 24DAA and 20DAA respectively and decreased towards maturity. Over all seed 
Fig. 1 Linolenic acid content of 34 flax accessions carrying identical isoforms for the fatty acid desaturases SAD1, SAD2, FAD2A, FAD2B, FAD3A and FAD3B. The sample means were averaged from two locations (MB and SK) over four years (2009, 2010, 2011 and 2012). Arrows indicate the accessions selected for the fatty acid desaturase gene expression study. Error bars represent the standard error of the mean. Letters above the bars indicate statistical significance of the Duncan's multiple range tests

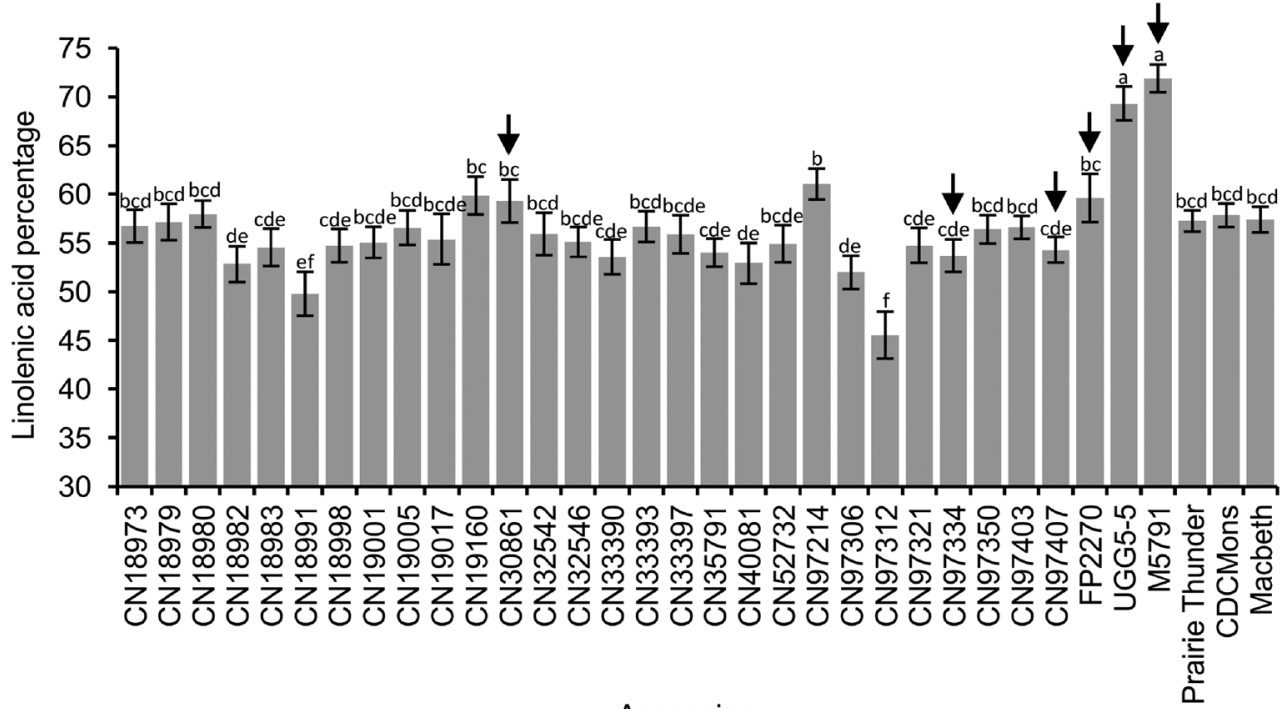

Accessions

developmental stages, sad and fad expression were not significant between genotypes $(\mathrm{P}=0.1400)$ (ESM 2, ESM 3). However, at 32 DAA, significant differential expression between genotypes was observed for $f a d 2 a, f a d 3 a$ and fad3b (ESM 4). Fad $2 a$ and $f a d 3 a$ were more highly expressed in the high-LIN line M5791 whereas fad3b was expressed at a lower level in FP2270 than in the other five genotypes (Table 2).

\section{Promoter analysis}

Promoter sequence analysis of $\mathrm{sad}$ and $\mathrm{fad}$ genes corresponding to bases from -800 to +200 relative to the TSS revealed single point mutations in the promoter region of $\mathrm{sad} 1$, $\mathrm{sad} 2$ and $f a d 3 b$ of CN30861 (ESM 5). Computational analysis of promoter regions of the six desaturase genes indicated the presence of several basic transcriptional elements such as CAAT and TATA boxes. In addition to these basic elements, many seed or endosperm specific and ABA-responsive ciselements (ABRE) including several Dof core (AAAG motif), DPBP core (ACACNNG motif), E-box (CANNTG motif), Myb-core (CNGTTR motif) and ACGT-box (AACGTT/ABRE motif) were identified. The sequence analysis also revealed the presence of motifs similar to pollen-specific cis-acting elements; POLLEN1LELAT52 (AGAAA) is one of two co-dependent regulatory elements responsible for the pollen-specific activation of genes (ESM 5).
Fig. 2 Fatty acid composition of CN97334, CN97407, CN30861, FP2270, UGG5-5 and M5791. Percentages of the five main fatty acids, namely palmitic (PAL, C16:0), stearic (STE, C18:0), oleic (OLE, C18:1), linoleic (LIO, C18:2) and linolenic (LIN, C18:3) acids for each genotype are illustrated. Error bars represent standard error of the mean. Letters beside or above the bars indicate statistical significance of the Duncan's multiple range tests

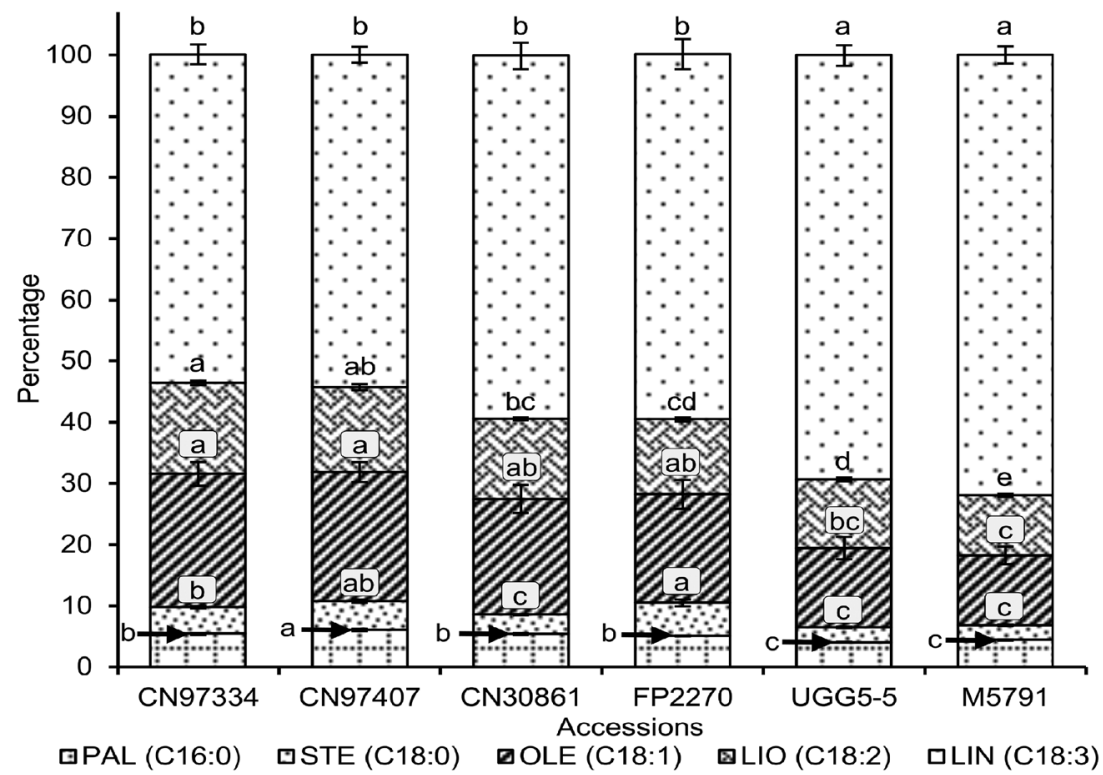




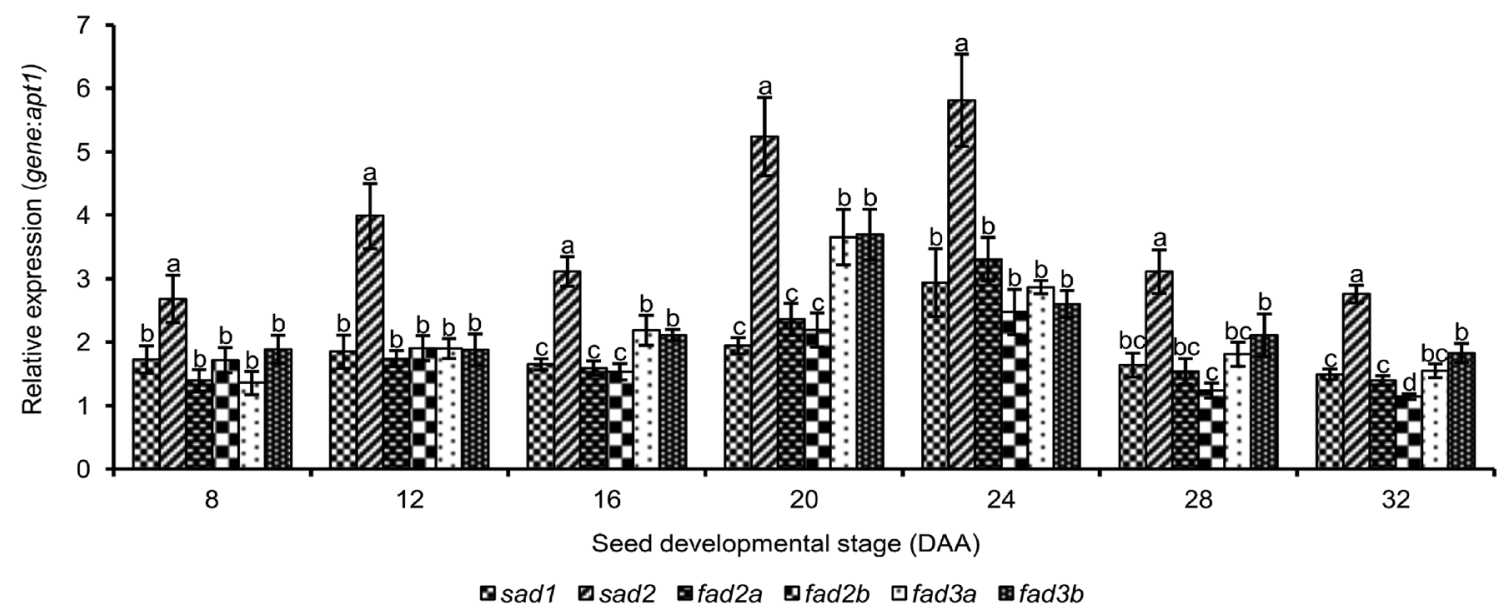

Fig. 3 Relative expression of the fatty acid desaturase genes $\operatorname{sad} 1$, sad2, $f a d 2 a, f a d 2 b, f a d 3 a$ and $f a d 3 b$ in flax during seed development. Error bars represent standard error of the mean and are based on three

\section{Phenotypic data}

All FA traits showed significant genotype (G), location (L) and year $(\mathrm{Y})$ effects $(\mathrm{P}<0.001$; ESM 6). Genotype by environment interactions (GEs: $\mathrm{G}^{*} \mathrm{~L}, \mathrm{G}^{*} \mathrm{Y}, \mathrm{L}^{*} \mathrm{Y}$ and $\mathrm{G}^{*} \mathrm{~L}^{*} \mathrm{Y}$ ) were also significant for all FA composition traits and oil content (ESM 6).

\section{Discussion}

FADs display significant diversity in their sequences and expression (Los and Murata 1998; Warude et al. 2006) and hence are considered biotechnological targets for manipulation of FA composition of oilseed crops (Khadake et al. 2009). Although the genetic variability for FADs and their impact on FA composition in flax has been recently reported (Thambugala et al. 2013), little is known about how the fad expression levels during seed development affect FA composition. In the present study, expression patterns of $\operatorname{sad1}$, sad2, $f a d 2 a, f a d 2 b, f a d 3 a$ and $f a d 3 b$ of six flax genotypes at various seed developmental stages were studied using semiquantitative RT-PCR analysis.

Semi-quantitative RT-PCR is a highly sensitive and specific method to analyse the expression of genes (Choquer et al. 2003). The reliability of this method depends on a number of factors including RNA quality, primer specificity, technique precision and use of a stable house-keeping gene (Wong and Medrano 2005; Banik et al. 2011). Although semiquantitative RT-PCR is mostly used as a qualitative method of analysing gene expression, the determination of both $\mathrm{fad}$ and apt 1 reference gene products by densitometric analysis enabled quantification and permitted comparisons across developmental stages, genes and genotypes (Choquer et al. independent RT-PCR replicates. Letters above the bars indicate statistical significance of the Duncan's multiple range tests

2003; Libus and Storchová 2006). The Arabidopsis apt1 gene has been identified as one of the most stable internal controls (Gutierrez et al. 2008) and the flax apt1 ortholog used in this study confirmed its consistent expression across all seed developmental stages and genotypes (Livak and Schmittgen 2001; Pfaffl 2005; Banik et al. 2011). Furthermore, the approach of quantifying cDNA precisely with the RiboGreen method reduces the variability associated with variations in starting material, hence adding precision to the evaluation method (Libus and Storchová 2006).

To establish correlations between gene expression and variation in FA composition, we examined expression patterns of sad and fad genes using six flax genotypes varying in LIN content. To our knowledge, this is the first report in flax comparing expression levels of all six desaturase genes and FA composition during seed development from genotypes that differed significantly in LIN content. Oil accumulation is a highly controlled developmental process. Genetic studies indicated that genes of the FA biosynthetic pathways, including triacylglycerol (TAG) synthesis, are regulated at the level of transcription (Baud and Graham 2006; O'Hara et al. 2002; Ohlrogge and Jaworski 1997). Gene expression programs related to FA synthesis are activated during the maturation phase and most genes encoding FA synthesis enzymes display a bell-shaped pattern of expression during seed development (Baud and Lepiniec 2009). Similarly, the six FA desaturases studied herein all displayed the bell-shaped pattern of expression with a peak at or after 20 DAA. Although the flax genome contains two paralogous sad loci, sad1 and sad2, they are differentially expressed (Jain et al. 1999) with sadl having lower and more constant expression throughout seed development. The highly conserved nature of sad2 and its higher expression are in agreement with its essential $\Delta 9$ desaturase role in the lipid biosynthetic pathway in flax (Allaby et al. 2005; Thambugala et al. 2013). 
Table 2 Expression of desaturase genes $s a d 1$, sad2, fad $2 a$, fad $2 b$, fad $3 a$ and $f a d 3 b$ during seed development of six flax genotypes

\begin{tabular}{|c|c|c|c|c|c|c|c|}
\hline \multirow[t]{2}{*}{ Seed developmental stage (DAA) } & \multirow[t]{2}{*}{ Genotype } & \multicolumn{6}{|c|}{ Relative expression (gene:apt 1 ) } \\
\hline & & sadl & $\operatorname{sad} 2$ & $f a d 2 a$ & $f a d 2 b$ & $f a d 3 a$ & $f a d 3 b$ \\
\hline \multirow[t]{6}{*}{8} & CN97334 & 1.0 & 1.9 & 0.8 & 1.4 & 0.9 & 1.3 \\
\hline & CN97407 & 2.1 & 3.8 & 1.5 & 2.0 & 1.4 & 2.0 \\
\hline & CN30861 & 1.6 & 3.3 & 1.4 & 2.1 & 1.8 & 2.3 \\
\hline & FP2270 & 2.0 & 2.3 & 1.3 & 1.9 & 0.8 & 1.9 \\
\hline & UGG5-5 & 1.7 & 2.2 & 1.2 & 1.3 & 1.2 & 1.4 \\
\hline & M5791 & 1.9 & 2.6 & 2.6 & 1.7 & 2.1 & 2.4 \\
\hline \multirow[t]{6}{*}{12} & CN97334 & 1.4 & 3.1 & 1.4 & 1.6 & 1.4 & 1.6 \\
\hline & CN97407 & 2.0 & 4.3 & 2.0 & 1.9 & 2.2 & 2.3 \\
\hline & CN30861 & 1.7 & 4.2 & 1.8 & 1.9 & 2.2 & 2.1 \\
\hline & FP2270 & 1.7 & 3.7 & 1.5 & 1.7 & 1.7 & 1.9 \\
\hline & UGG5-5 & 2.2 & 4.6 & 2.1 & 2.4 & 2.1 & 1.9 \\
\hline & M5791 & 2.1 & 4.1 & 1.7 & 1.9 & 1.8 & 1.6 \\
\hline \multirow[t]{6}{*}{16} & CN97334 & 1.6 & 2.3 & 1.7 & 1.5 & 1.5 & 2.0 \\
\hline & CN97407 & 1.4 & 2.6 & 1.5 & 1.4 & 2.2 & 2.0 \\
\hline & CN30861 & 2.1 & 4.1 & 1.9 & 1.8 & 3.2 & 2.5 \\
\hline & FP2270 & 1.6 & 3.3 & 1.7 & 1.6 & 2.4 & 2.0 \\
\hline & UGG5-5 & 1.5 & 3.2 & 1.4 & 1.3 & 2.1 & 2.1 \\
\hline & M5791 & 1.8 & 3.2 & 1.3 & 1.6 & 1.7 & 2.1 \\
\hline \multirow[t]{6}{*}{20} & CN97334 & 1.9 & 5.1 & 2.2 & 2.4 & 3.0 & 3.2 \\
\hline & CN97407 & 1.9 & 6.2 & 2.0 & 2.2 & 3.7 & 4.1 \\
\hline & CN30861 & 2.2 & 6.0 & 3.0 & 2.7 & 4.5 & 4.4 \\
\hline & FP2270 & 1.8 & 5.2 & 2.1 & 2.1 & 3.7 & 3.7 \\
\hline & UGG5-5 & 1.7 & 4.6 & 2.4 & 1.8 & 3.5 & 3.5 \\
\hline & M5791 & 2.2 & 4.3 & 2.4 & 2.0 & 3.6 & 3.3 \\
\hline \multirow[t]{6}{*}{24} & CN97334 & 3.1 & 5.9 & 3.8 & 2.8 & 2.8 & 2.4 \\
\hline & CN97407 & 2.7 & 5.5 & 3.0 & 2.0 & 2.6 & 2.3 \\
\hline & CN30861 & 3.0 & 6.5 & 3.0 & 2.6 & 3.0 & 2.3 \\
\hline & FP2270 & 2.8 & 6.1 & 3.2 & 2.4 & 2.8 & 2.7 \\
\hline & UGG5-5 & 2.7 & 5.0 & 3.4 & 2.3 & 3.1 & 3.1 \\
\hline & M5791 & 3.3 & 6.0 & 3.4 & 2.8 & 2.9 & 2.8 \\
\hline \multirow[t]{6}{*}{28} & CN97334 & 1.6 & 3.8 & 1.4 & 1.3 & 1.6 & 3.0 \\
\hline & CN97407 & 1.4 & 3.3 & 1.5 & 1.1 & 1.5 & 2.1 \\
\hline & CN30861 & 1.7 & 4.0 & 1.6 & 1.5 & 2.2 & 2.4 \\
\hline & FP2270 & 1.9 & 2.9 & 1.4 & 1.4 & 2.0 & 2.0 \\
\hline & UGG5-5 & 1.7 & 3.2 & 1.7 & 1.3 & 1.9 & 1.8 \\
\hline & M5791 & 1.5 & 1.6 & 1.7 & 0.9 & 1.7 & 1.3 \\
\hline \multirow[t]{6}{*}{32} & CN97334 & 1.4 & 2.9 & $1.3^{\mathrm{b}}$ & 1.2 & $1.5^{\mathrm{b}}$ & $2.0^{\mathrm{a}}$ \\
\hline & CN97407 & 1.3 & 2.8 & $1.3^{\mathrm{b}}$ & 1.1 & $1.6^{\mathrm{ab}}$ & $2.2^{\mathrm{a}}$ \\
\hline & CN30861 & 1.6 & 2.5 & $1.3^{\mathrm{b}}$ & 1.2 & $1.6^{\mathrm{ab}}$ & $2.3^{\mathrm{a}}$ \\
\hline & FP2270 & 1.6 & 3.1 & $1.3^{\mathrm{b}}$ & 1.2 & $0.8^{\mathrm{c}}$ & $0.7^{\mathrm{b}}$ \\
\hline & UGG5-5 & 1.4 & 2.6 & $1.3^{\mathrm{b}}$ & 0.9 & $1.8^{\mathrm{ab}}$ & $1.6^{\mathrm{a}}$ \\
\hline & M5791 & 1.7 & 2.7 & $1.9^{\mathrm{a}}$ & 1.3 & $2.1^{\mathrm{a}}$ & $2.0^{\mathrm{a}}$ \\
\hline
\end{tabular}

a,b,c Statistical significance $(p<0.05)$ of Duncan's multiple range tests among genotypes within each gene and developmental stage

Transcriptional control of $f a d$ gene expression in flax has been demonstrated (Fofana et al. 2006; Banik et al. 2011). The two paralogous $f a d 2 a$ and $f a d 2 b$ genes have been cloned and characterized from flax (Krasowska et al. 2007; Khadake et al. 2009). Both genes displayed relatively low but steady expression patterns throughout seed development. Fofana et al. 
(2006) demonstrated the seed-specific expression of $f a d 2 a$ while constitutive expression of $f a d 2 b$ has also been reported (Cao et al. 2013; Schlueter et al. 2007). Fad $3 a$ and fad $3 b$ had similar expression patterns as the other four desaturase genes except that their expression peaked at 20 DAA instead of 24 as previously shown for other flax accessions by Banik et al. (2011) who also demonstrated that the $f a d 3$ expression correlated with LIN accumulation during seed development.

$\mathrm{Fad} 2$ genes are thought to be the rate-limiting genes of the FA biosynthesis pathway in flax and are highly influenced by the environment (Fofana et al. 2006). The significant GE interaction observed for FA traits also suggests the complex interactions of gene and environmental cues on FA composition. Temperature during the growing season affects FA composition of flax and other oil crops (Casa et al. 1999; Fofana et al. 2006; Baud and Lepiniec 2010). The higher thermal stability of safflower's FAD2 compared to that of sunflowers was proposed to explain the more stable FA composition of safflower irrespective of the temperature during seed development (Esteban et al. 2004). Effects of varying temperature on sad gene expression alters the FA composition of soybean seeds (Byfield and Upchurch 2007).

Identification of molecular components that regulate expression patterns of FA biosynthesis genes is important for understanding the variation in FA composition in flax. Activators and repressors fine-tune the expression level of FA biosynthetic pathway genes (Bene et al. 2001; Baud and Lepiniec 2010; Saed Taha et al. 2012). An AW-box sequence $[\mathrm{CnTnG}](\mathrm{n})_{7}[\mathrm{CG}]$ identified in the promoter regions of several FA biosynthetic genes was proposed to be recognized by WRI1, a transcription factor responsible for activating these genes (Maeo et al. 2009; Baud et al. 2007). Although promoters of the six desaturase genes share a functionally similar promoter core, their expression can be modulated by differences in upstream regulatory elements. Kim et al. (2006) reported that the strong seed specific expression of the sesame $\mathrm{fad} 2$ gene is controlled by negative cis-regulatory elements of the promoter and enhancers located in the 5'-UTR (untranslated region). Temporal control of $f a d 2$ via ABA-response elements was also reported (Kim et al. 2006). However, the functions of these putative regulatory elements for the expression of FAD genes in flax are yet to be determined.

Millar and Kunst (1999) reported that the natural genetic variation of the FA composition of seed oils in different ecotypes of Arabidopsis thaliana are probably due to altered expression levels or activities of FA biosynthetic enzymes. Here, we looked at the expression levels of six desaturase genes in six genotypes that differed for FA composition but that encoded the same desaturase isoforms and we were unable to establish correlations between the expression of any of the desaturase genes with the FA composition of the six flax genotypes. Two main hypotheses provide potential explanations for our results. First, genetic factors other than the six desaturases studied here may play an important role in determining the FA composition of flax. Although desaturases and thioesterases are the major enzymes responsible for FA composition in oilseed crops (Ohlrogge and Jaworski 1997; Baud and Lepiniec 2010), minor genes may play an important role in determining the FA composition variation. Complete genome sequences of many plant species have indeed allowed the identification of a number of genes involved in plant oil biosynthesis (Ying et al. 2012). However, the factors leading to variations in FA composition remain to be fully understood (Hobbs et al. 2004; Keurentjes et al. 2006). Genes of minor effect have generally been considered responsible for variation observed in LIN content in several oil crops including flax (Das and Rai 1974; Doucet and Filipescu 1981; Green 1986; Cloutier et al. 2010), rapeseed (Kondra and Thomas 1975; Pleines and Friedt 1989) and soybean (White et al. 1961). Green (1986) reported that the small differences in LIN content between 'Glenelg' and the majority of current flax varieties are most probably due to the cumulative effects of several minor genes that modify the expression of $f a d 3 a$ and $\mathrm{fad} 3 \mathrm{~b}$ (Vrinten et al. 2005). QTL and association mapping may help in identifying minor genes controlling FA composition (Soto-Cerda et al. 2013). Of these putative minor genes, Lei et al. (2012) suggested that acyl carrier protein (ACP), 3ketoacyl-ACP-synthase (KAS) and acyl-ACP thioesterase (FATA) play a role in FA composition and may also be rate limiting. ACP, KAS and FATA gene expression correlated significantly with monounsaturated FA and PUFA synthesis (Lei et al. 2012). Similarly, natural variation in long chain FA content in Arabidopsis thaliana was found to be controlled by a new isoform of $\beta$-ketoacyl-CoA synthase 18 (KCS18; Jasinski et al. 2012).

The second hypothesis is that differential expression of desaturases can indeed explain FA compositional differences in lines with identical isoforms grown in the field but that we could not demonstrate it because we measured the expression under controlled conditions. Environment and genotype by environment significantly affect FA composition (Deng and Scarth 1998; Hernández et al. 2011). The effect of the environment on $\mathrm{fad} 2$ expression in flax has been documented (Fofana et al. 2006). It is therefore conceivable that correlations may exist between desaturase expression levels and FA composition if the former was measured in the same field environment as the latter. This second hypothesis is not mutually exclusive to the minor genes hypothesis because minor genes could be responsible for translating the environmental cues that affect expression of desaturases. Further studies of desaturase gene expression in field environments combined with phenotyping of the genotypes in the same environments are needed to elucidate and partition the role of the genetic and environmental factors in FA composition in flax.

Seed FA composition has become a major target for modification by plant breeding and genetic engineering in many 
oil crops for food and non-food purposes (Murphy 1996; Damude and Kinney 2008; Cahoon et al. 2010). A greater understanding of the genetic control of the FA composition of linseed oil is essential to develop flax cultivars producing oils for specific end-uses. The current study provides some thought-provoking hints to understand the genetic components such as transcription factors and genes other than the FA desaturases, controlling FA composition in flax, but further investigations are required to fill the knowledge gap.

Acknowledgments We are thankful to Drs Scott Duguid, Gordon Rowland and Helen Booker and their teams for providing the phenotypic data. This work was conducted as part of the Total Utilization Flax Genomics (TUFGEN) project funded by Genome Canada and other stakeholders. Project management and support by Genome Prairie are also gratefully acknowledged.

Conflict of interest The authors declared that they have no conflict of interest.

Open Access This article is distributed under the terms of the Creative Commons Attribution License which permits any use, distribution, and reproduction in any medium, provided the original author(s) and the source are credited.

\section{References}

Allaby RG, Peterson GW, Merriwether DA, Fu YB (2005) Evidence of the domestication history of flax (Linum usitatissimum L.) from genetic diversity of the sad2 locus. Theor Appl Genet 112:58-65

Ander BP, Weber AR, Rampersad PP, Gilchrist JSC, Pierce GN, Lukas A (2004) Dietary flaxseed protects against ventricular fibrillation induced by ischemia-reperfusion in normal and hypercholesterolemic rabbits. J Nutr 134:3250-3256

Banik M, Duguid S, Cloutier S (2011) Transcript profiling and gene characterization of three fatty acid desaturase genes in high, moderate and low linolenic acid genotypes of flax (Linum usitatissimum L.) and their role in linolenic acid accumulation. Genome 54:471-483

Baud S, Graham IA (2006) A spatiotemporal analysis of enzymatic activities associated with carbon metabolism in wild-type and mutant embryos of Arabidopsis using in situ histochemistry. Plant J 46: 155-169

Baud S, Lepiniec L (2009) Regulation of de novo fatty acid synthesis in maturing oilseeds of Arabidopsis. Plant Physiol Biochem 47:448-455

Baud S, Lepiniec L (2010) Physiological and developmental regulation of seed oil production. Prog Lipid Res 49:235-249

Baud S, Mendoza MS, To A, Harscoët E, Lepiniec L, Dubreucq B (2007) WRINKLED1 specifies the regulatory action of LEAFY COTYLEDON2 towards fatty acid metabolism during seed maturation in Arabidopsis. Plant J 50:825-838

Bene H, Lasky D, Ntambi JM (2001) Cloning and characterization of the human stearoyl-coa desaturase gene promoter: transcriptional activation by sterol regulatory element binding protein and repression by polyunsaturated fatty acids and cholesterol. Biochem Biophys Res Commun 284:1194-1198

Byfield GE, Upchurch RG (2007) Effect of temperature on delta-9 stearoyl-ACP and microsomal omega- 6 desaturase gene expression and fatty acid content in developing soybean seeds. Crop Sci 47 : 1698-1704
Cahoon E, Clemente T, Damude H, Kinney A (2010) Modifying vegetable oils for food and non-food purposes. In: Vollmann J, Rajcan I (eds) Oil crops. Springer, New York, pp 31-56

Cao S, Zhou XR, Wood CC, Green AG, Singh SP, Liu L, Liu Q (2013) A large and functionally diverse family of $\mathrm{Fad} 2$ genes in safflower (Carthamus tinctorius L.). BMC Plant Biol 13:5

Casa R, Russell G, Lo Cascio B, Rossini F (1999) Environmental effects on linseed (Linum usitatissimum L.) yield and growth of flax at different stand densities. Eur J Agron 11:267-278

Chang WC, Lee TY, Huang HD, Huang HY, Pan RL (2008) PlantPAN: Plant Promoter Analysis Navigator, for identifying combinatorial cis-regulatory elements with distance constraint in plant gene group. BMC Genomics 9:561

Choquer M, Boccara M, Vidal-Cros A (2003) A semi-quantitative RTPCR method to readily compare expression levels within Botrytis cinerea multigenic families in vitro and in planta. Curr Genet 43 : 303-309

Cloutier S, Ragupathy R, Niu Z, Duguid S (2010) SSR-based linkage map of flax (Linum usitatissimum L.) and mapping of QTLs underlying fatty acid composition traits. Mol Breed 28:437-451

Damude HG, Kinney AJ (2008) Engineering oilseeds to produce nutritional fatty acids. Physiol Plant 132:1-10

Das K, Rai M (1974) A diallel analysis of iodine value in linseed. Indian J Genet Plant Breed 34:718-725

Deng X, Scarth R (1998) Temperature effects on fatty acid composition during development of low-linolenic oilseed rape (Brassica napus). J Am Oil Chem Soc 75:759-766

Doucet I, Filipescu H (1981) Inheritance and content of unsaturated fatty acids in linseed. An Inst Cercet Cereale Plante Teh Fundulea 46:35-48

Dyer JM, Stymne S, Green AG, Carlsson AS (2008) High-value oils from plants. Plant J 54:640-655

Esteban AB, Sicardo MD, Mancha M, Martinez-Rivas JM (2004) Growth temperature control of the linoleic acid content in safflower (Carthamus tinctorius) seed oil. J Agric Food Chem 52:332-336

Ewing B, Hillier L, Wendl MC, Green G (1998) Base-calling of automated sequencer traces using PHRED: I. accuracy assessment. Genome Res 8:175-185

Fofana B, Duguid S, Cloutier S (2004) Cloning of fatty acid biosynthetic genes $\beta$-Ketoacyl CoA synthase, fatty acid elongase, stearoyl-ACP desaturase, and fatty acid desaturase and analysis of expression in the early developmental stages of flax (Linum usitatissimum L.) seeds. Plant Sci 166:1487-1496

Fofana B, Cloutier S, Duguid S, Ching J, Rampitch C (2006) Gene expression of stearoyl-ACP desaturase and $\Delta 12$ fatty acid desaturase 2 is modulated during seed development of flax (Linum usitatissimum). Lipids 41:705-712

Fofana B, Ragupathy R, Cloutier S (2010) Flax Lipids: Classes, biosynthesis, genetics and the promise of applied genomics for understanding and altering of fatty acids. In: Gilmore PL (ed) Lipids: Categories, biological functions and metabolism, nutrition, and health. Nova Science, New York, pp 71-98

Green AG (1986) Genetic control of polyunsaturated fatty acid biosynthesis in flax (Linum usitatissimum) seed oil. Theor Appl Genet 72: 654-661

Gutierrez L, Mauriat M, Guénin S, Pelloux J, Lefebvre JF, Louvet R et al (2008) The lack of a systematic validation of references genes: a serious pitfall undervalued in reverse transcription-polymerase chain reaction (RT-PCR) analysis in plants. Plant Biotechnol J 6:609-618

Hernández ML, Padilla MN, Sicardo MD, Mancha M, Martínez-Rivas JM (2011) Effect of different environmental stresses on the expression of oleate desaturase genes and fatty acid composition in olive fruit. Phytochemistry $72: 178-187$

Higo K, Ugawa Y, Iwamoto M, Korenaga T (1999) Plant cis-acting regulatory DNA elements (PLACE) database. Nucleic Acids Res 27:297-300 
Hobbs DH, Flintham JE, Hills MJ (2004) Genetic control of storage oil synthesis in seeds of Arabidopsis. Plant Physiol 136:3341-3349

Huang X, Madan A (1999) CAP3: a DNA sequence assembly program. Genome Res 9:868-877

Jain RK, Thomson RG, Taylor DC, MacKenzie SL, McHughen A, Rowland GG, Tenaschuk D, Coffey M (1999) Isolation and characterization of two promoters from linseed for genetic engineering. Crop Sci 39:1696-1701

Jasinski S, Lécureuil A, Miquel M, Loudet O, Raffaele S, Froissard M, Guerche P (2012) Natural variation in seed very long chain fatty acid content is controlled by a new isoform of KCS18 in Arabidopsis thaliana. PLoS One 7:e49261

Keurentjes JJ, Fu J, de Vos CH, Lommen A, Hall RD, Bino RJ, vander Plas LH, Jansen RC, Vreugdenhil D, Koornneef M (2006) The genetics of plant metabolism. Nat Genet 38:842-848

Khadake RM, Ranjekar PK, Harsulkar AM (2009) Cloning of a novel omega-6 desaturase from flax (Linum usitatissimum) and its functional analysis in Saccharomyces cerevisiae. Mol Biotechnol 42: $168-174$

Khadake R, Khonde V, Mhaske V, Ranjekar P, Harsulkar A (2011) Functional and bioinformatic characterisation of sequence variants of Fad3 gene from flax. J Sci Food Agric 91:2689-2696

Kim MJ, Kim H, Shin JS, Chung CH, Ohlrogge JB, Suh MC (2006) Seed-specific expression of sesame microsomal oleic acid desaturase is controlled by combinatorial properties between negative cis-regulatory elements in the SeFAD2 promoter and enhancers in the 5'-UTR intron. Mol Genet Genomics 276:351-368

Kondra ZP, Thomas PM (1975) Inheritance of oleic, linoleic and linolenic acids in seed oil of rapeseed (Brassica napus). Can J Plant Sci 55: 205-210

Krasowska A, Dziadkowiec D, Polinceusz A, Plonka A, Łukaszewicz M (2007) Cloning of flax oleic fatty acid desaturase and its expression in yeast. J Am Oil Chem Soc 84:809-816

Kumar S, Jordan MC, Datla R, Cloutier S (2013) The LuWD40-1 gene encoding WD repeat protein regulates growth and pollen viability in flax (Linum usitatissimum L.). PLoS One 8:369124

Lei A, Chen H, Shen G, Hu Z, Chen L, Wang J (2012) Expression of fatty acid synthesis genes and fatty acid accumulation in haematococcus pluvialis under different stressors. Biotechnol Biofuels 5:18

Libus J, Storchová H (2006) Quantification of cDNA generated by reverse transcription of total RNA provides a simple alternative tool for quantitative RT-PCR normalization. Biotechniques 41:156-158

Lin CS, Poushinsky G (1985) A modified augmented design (type 2) for rectangular plots. Can J Plant Sci 65:743-749

Livak KJ, Schmittgen TD (2001) Analysis of relative gene expression data using real-time quantitative PCR and the $2^{-\Delta \Delta} \mathrm{CT}$ method. Methods 25:402-408

Los DA, Murata N (1998) Structure and expression of fatty acid desaturases. Biochim Biophys Acta 1394:3-15

Maeo K, Tokuda T, Ayame A, Mitsui N, Kawai T, Tsukagoshi H, Ishiguro S, Nakamura K (2009) An AP2-type transcription factor, WRINKLED1, of Arabidopsis thaliana binds to the AW-box sequence conserved among proximal upstream regions of genes involved in fatty acid synthesis. Plant J 60:476-487

Millar AA, Kunst L (1999) The natural genetic variation of the fatty-acyl composition of seed oils in different ecotypes of Arabidopsis thaliana. Phytochemistry 52:1029-1033

Muir A, Westcott N (2003) Flax: the genus Linum. Taylor \& Francis, London, UK, p 307

Murphy DJ (1996) Engineering oil production in rapeseed and other oil crops. Trends Biotechnol 14:206-213

O'Hara P, Slabas AR, Fawcett T (2002) Fatty acid and lipid biosynthetic genes are expressed at constant molar ratios but different absolute levels during embryogenesis. Plant Physiol 129:310-320

Ohlrogge JB, Jaworski JG (1997) Regulation of fatty acids synthesis. Annu Rev Plant Physiol Plant Mol Biol 48:109-136
Oomah BD (2001) Flaxseed as a functional food source. J Sci Food Agric 81:889-894

Pfaffl MW (2005) Quantification strategies in real time PCR. In: Bustin SA (ed) A-Z of quantitative PCR. International University Line, La Jolla, CA, pp 87-112

Pleines S, Friedt W (1989) Genetic control of linolenic acid concentration in seed oil of rapeseed (Brassica napus L.). Theor Appl Genet 78:793-797

Reese MG (2001) Application of a time-delay neural network to promoter annotation in the Drosophila melanogaster genome. Comp Chem 26:51-56

Rozen S, Skaletsky H (2000) Primer3 on the WWW for general users and for biologist programmers. Methods Mol Biol 132:365-386

Saed Taha R, Ismail I, Zainal Z, Abdullah SN (2012) The stearoyl-acyl-carrierprotein desaturase promoter (Des) from oil palm confers fruit specific GUS expression in transgenic tomato. J Plant Physiol 169:1290-1300

Schlueter JA, Vasylenko-Sanders IF, Deshpande S, Yi J, Siegfried M, Roe BA, Schlueter SD, Scheffler BE, Shoemaker RC (2007) The FAD2 gene family of soybean: insights into the structural and functional divergence of a paleopolyploid genome. Crop Sci 47:S14-S26

Shanklin J, Cahoon EB (1998) Desaturation and related modifications of fatty acids. Annu Rev Plant Physiol Plant Mol Biol 49:611-641

Singh S, McKinney S, Green A (1994) Sequence of a cDNA from Linum usitatissimum encoding the stearoyl-ACP carrier protein desaturase. Plant Physiol 140:1075

Smooker AM, Wells R, Morgan C, Beaudoin F, Cho K, Fraser F, Bancroft I (2011) The identification and mapping of candidate genes and QTL involved in the fatty acid desaturation pathway in Brassica napus. Theor Appl Genet 122:1075-1090

Sorensen BM, Furukawa-Stoffer TL, Marshall KS, Page EK, Mir Z, Forster RJ, Weselake RJ (2005) Storage lipid accumulation and acyltransferase action in developing flaxseed. Lipids 40:1043-1049

Soto-Cerda BJ, Duguid S, Booker H, Diederichsen A, Cloutier S (2013) Association mapping of seed quality traits using the flax (Linum usitatissimum L.) core collection. Theor Appl Genet (in press)

Thambugala D, Duguid S, Loewen E, Rowland G, Booker H, You FM, Cloutier S (2013) Genetic variation of six desaturase genes in flax and their impact on fatty acid composition. Theor Appl Genet 126: $2627-2641$

Thompson JD, Higgins DG, Gibson TJ (1994) CLUSTAL W: improving the sensitivity of progressive multiple sequence alignment through sequence weighting, position-specific gap penalties and weight matrix choice. Nucleic Acids Res 22:4673-4680

Vrinten P, Hu Z, Munchinsky MA, Rowland G, Qiu X (2005) Two FAD3 desaturase genes control the level of linolenic acid in flax seed. Plant Physiol 139:79-87

Warude D, Joshi K, Harsulkar A (2006) Polyunsaturated fatty acids: biotechnology. Crit Rev Biotechnol 26:83-93

White HB Jr, Quackenbush FW, Probst AH (1961) Occurrence and inheritance of linolenic and linoleic acids in soybean seeds. J Am Oil Chem Soc 38:113-117

Wiesenfeld PW, Babu US, Collins TFX, Sprando R, O’Donnell MW, Flynn TJ, Black T, Olejnick N (2003) Flaxseed increased $\alpha$-linolenic and eicosapentaenoic acid and decreased arachidonic acid in serum and tissues of rat dams and offspring. Food Chem Toxicol 41:841-855

Wong ML, Medrano JF (2005) Real-time PCR for mRNA quantitation. Biotechniques 39:75-85

Ying JZ, Shan JX, Gao JP, Zhu MZ, Shi M, Lin HX (2012) Identification of quantitative trait loci for lipid metabolism in rice seeds. Mol Plant 5:865-875

You FM, Duguid S, Thambugala D, Cloutier S (2013) Statistical analysis and field evaluation of the type 2 modified augmented design (MAD) in phenotyping of flax (Linum usitatissimum) germplasm in multiple environments. Aust J Crop Sci 7:1789-1800

Zuk M, Prescha A, Stryczewska M, Szopa J (2012) Engineering flax plants to increase their antioxidant capacity and improve oil composition and stability. J Agric Food Chem 60:5003-5012 